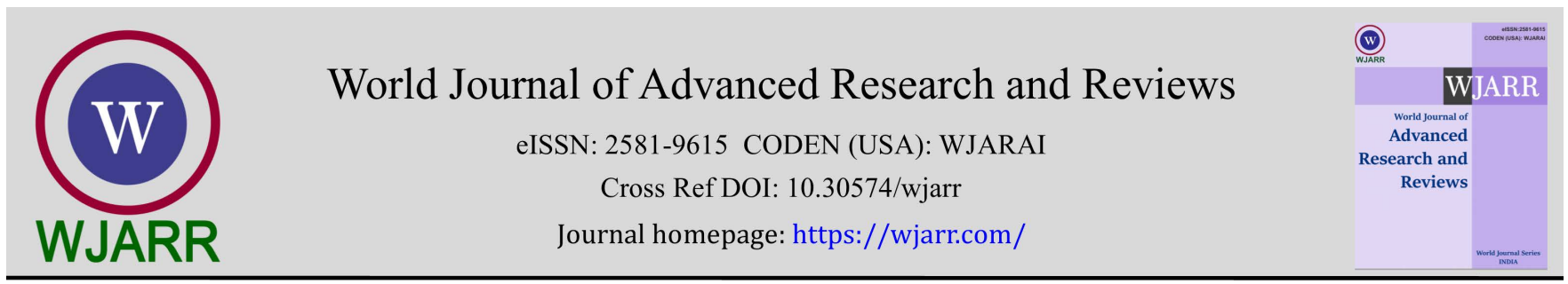

(RESEARCH ARTICLE)

Check for updates

\title{
Life satisfaction and psychological wellbeing among young adults
}

\author{
Iram Fatima 1, Muhammad Waqar Naeem ${ }^{2}$ and Hafiz Muhammad Zeeshan Raza ${ }^{3, *}$ \\ ${ }^{1}$ MS Scholar, Department of Applied Psychology, Government Sadiq College, Women University Bahawalpur, Punjab, \\ Pakistan. \\ 2, MS Scholar, Department of Law and Economics, Islamia University of Bahawalpur, Punjab, Pakistan. \\ ${ }^{3}$ Research Associate, Genomics and Computational Biology Laboratory, COMSATS University Islamabad, Sahiwal Campus, \\ Punjab, Pakistan.
}

World Journal of Advanced Research and Reviews, 2021, 12(02), 365-371

Publication history: Received on 09 October 2021; revised on 13 November 2021; accepted on 15 November 2021

Article DOI: https://doi.org/10.30574/wjarr.2021.12.2.0599

\begin{abstract}
Life satisfaction is required for positive mental health and positive mental health is related to psychological wellbeing. The study intended to evaluate the relation between psychological wellbeing (purpose of life, self-acceptance, environmental mastery, and positive relations) and life satisfaction among young adults. Purposive sample technique was used to get the sample. Young adults $(\mathrm{N}=200)$ from different educational organization of Bahawalpur (Pakistan) were included in the research as sample. Demographic form, satisfaction with life scale and psychological-wellbeing scale were administered to assess the level of psychological wellbeing and life satisfaction of young adults. For statistical analysis, independent t-test, regression, and correlation were performed. Results showed that life satisfaction is positively linked with psychological health. Positive relations and self-acceptance is greater predictor of purpose in life. Females were found having more life satisfaction and psychological health.
\end{abstract}

Keywords: Psychological wellbeing; Self-acceptance; Life satisfaction; Mental health; Student health

\section{Introduction}

Life satisfaction is an important construct in positive psychology. Many people face problems in their life but young adults have more adjustment problems as well as they have to tackle their increasing social circle [1]. Change is a rule for life as time passes person have to modify him and they have to face many challenges in their life. Because adolescents leaving that stage of life and becoming adults so they have to face many challenges as well as mental health issues. But after a long time it is defined in positive ways. That is, psychological well-being is not only absence of distressful symptoms. Models of positive functioning has basic concept that to modify and increase individual strength and capacities that increase one's psychological wellbeing and that is a protective factor against psychological distress [2].

Absence of psychological wellbeing leads to many mental health problems for all of us but young adult is very sensitive for these mental health problems because they are growing as well as their social circle increasing and their responsibilities also growing [3]. Persons who have less positive psychological wellbeing they face many problems in daily dealings and less positive psychological wellbeing is related to increase psychological distress symptoms. When one has difficulty in daily dealings and distress symptoms are associated with it, he/she faces stress, anxiety and depression and that person surely has negative self-statements, his job life negatively affected and likely to experience impairment in productivity of work [4].

\footnotetext{
* Corresponding author: Hafiz Muhammad Zeeshan Raza

Genomics and Computational Biology Laboratory, COMSATS University Islamabad, Sahiwal Campus, Punjab, Pakistan. 
Opposite of less or diminished psychological wellbeing, people have positive functioning and increase psychological wellbeing that has shown to anticipate successful identity formation [5]. And some studies have shown that psychological wellbeing is protective element against stress and helpful to cope up with trauma. Our body and mind are interrelated. Healthy body has healthy mind. So when someone is psychologically healthy his physical health also affected [6]. Psychological wellbeing is related to positive physical health. For a healthy life and positive physical health one has to adapt healthy behaviors such as not eating between meals, exercise and proper sleep etc. A study has shown that positive psychological wellbeing is related to improvement in sleep quality [7].

Everyone has basic needs. Some of them are physical and some are psychological. Physical needs include food, oxygen and psychological needs are to be loved or have competence, needs differ subjectively [8]. When psychological needs fulfill person feels integrity, acceptance from society, meaning in life, personal growth and wellbeing. Young adults have many problems. Some are related to academic. Psychological wellbeing is beneficial for them to live a healthy life [9]. The shift from childhood to adulthood is a great stressor that cause decrease in psychological wellbeing. Someone wants to go college intrinsically and other doesn't want to go to college. One desire to spent leisure time with friends in gossips and some other wants to spend it on physical activities. Research had shown that spending leisure time in physical activities in colleges is linked to psychological wellbeing [10].

Acquiring a higher level of environmental mastery can make you happier. Happiness naturally arises from mastering critical aspects of life such as health, relationships, money, education, leisure, career, opportunity, change, and other environmental difficulties [9]. When one person achieves mastery he is able to deal effectively with life difficulties and other difficulties related to one's surroundings. Ability to cope with difficult situation and ability to manage your environment according to your desire and values make person happy [11]. The more the person happy with his life more the satisfy with his life. In older adults, environmental mastery seen as sense of control on environment and other outcome in life, environmental mastery is negatively associated with mortality causes such as cardiovascular diseases. Longitudinal investigation indicates that mastery often increases from adolescence until midlife and then drops [12].

Many of mental health issues exist in society and sometime specific issue is related to specific age. Young adults are productive part of every society [13]. Adults run their nation to the ways of progress. If they have mental issues and not satisfy with life his activities also hamper and this is great loss to society. This study is very helpful for mental health professionals. To deals with adults and resolve their issues in effective ways. It is the purpose of this study to contribute to the growing body of knowledge in the field of psychological well-being and life satisfaction. An important part of this research is examining young people' experiences of life satisfaction in relation to such factors as environmental mastery, self-acceptance, good interpersonal connections and a sense of purpose in their lives. Life satisfaction has a substantial correlation to one's psychological well-being. The lives of people with low mental health are not going to be happy ones. This combination of variables is missing in literature and it reveals important and useful aspects about young adults. Young adults have more psychological problems if these satisfied in young life then it will be helpful to get progress in later life. Most of researches deal with children and adolescent only few researches deal with young adults. For the purpose of allowing research into techniques to assist people achieve high levels of contentment at a young age.

\section{Aim}

This study was aimed to find out relationship between life satisfaction, self-acceptance and environmental mastery. It also located the relationship between life satisfaction, positive relations with others and purpose in life. It was also aimed to hit upon gender differences on life satisfaction and psychological wellbeing.

\section{Methods}

\subsection{Research design}

A quantitative, cross-sectional and co relational research design was used for the study.

\subsection{Participants characteristics}

Total no of $(N=200)$ of both gender male $(n=100)$ and female $(n=100)$ included from educational organizations of Bahawalpur. Participants selected from Govt. Sadiq College Women University Bahawalpur, Islamia University Bahawalpur, S.E College Bahawalpur and Allama Iqbal College. 


\subsubsection{Inclusion criteria}

The target population of the study was young adults from 18-24 ages and without any psychological disorder and physical disease. The entire sample was selected from lower, middle and upper class.

\subsubsection{Exclusion criteria}

Physically disabled and participant with psychological disorder was excluded from study. Older and children was also excluded from study. Who have any psychological history also excluded.

\subsection{Sampling}

The study was conducted in educational organizations of Bahawalpur including Govt. Sadiq College Women University Bahawalpur, Islamia University Bahawalpur, SE College Bahawalpur and Allama Iqbal College. Purposive sampling technique was used to get relevant participants. The sample was consisted of 200 participants. The ages of participant range from 18-24. Researcher approached to Danielsoper website ("Danielsoper, "2006). Because of initial model of research was multiple regression so the researcher used effect size 0.15 , statistical power 0.85 and significant level 0.05 . The minimum sample size was 98 and the researcher selected 200 participants for the study.

\subsection{Procedure}

Researcher approached to educational organizations of Bahawalpur including Govt. Sadiq College Women University Bahawalpur, Islamia University Bahawalpur and SE College Bahawalpur, Allama Iqbal College. Questionnaires were used in the study and informed consent also was provided to participants. Participants who agreed to participate in the study had to complete a consent form. When it came time for the participants to fill out their demographic information, the researcher used the self-developed demographic information sheet (DIS). Age, gender, education level and marital status were only a few of the demographics on the sheet. Participants who met the study's inclusion criteria were enrolled in the research and given the opportunity to complete further research surveys. It was the identical process and environment for administering the surveys that the researcher used to conduct the satisfaction with life scale (SWLS) and psychological wellbeing scale (PWB).

\subsection{Data Collection}

Participants were asked to score each item that best represents their experience with the provided statement on a scale of one to ten. Participants score their comments on a 6-point Likert scale ranging from 1 to 6 , with 1 indicating strong disagreement and 6 indicating strong agreement. Negatively phrased items are scored in the opposite direction, with higher subscale scores indicating stronger perceived positive functioning in the respective area. Per subscale, total scores might vary from 14 to 84 . The SPWB has been shown to have high psychometric qualities. As, internal consistency coefficients range from 0.83 to 0.91 per subscale: Purpose in Life $(\alpha=0.88)$, Positive Relations with Others ( $\alpha=0.88$ ), Environmental Mastery $(\alpha=.86)$, and Self-Acceptance $(\alpha=0.91)$. The 14 -item subscales' correlations with their own 20 -item original subscale vary from 0.97 to 0.99 , indicating that the components were tested consistently despite the reduction in test items. In environmental mastery scale item number 2, 3, 5, 8, 11 and 13 were reverse scored. And in positive relations scale item number $2,3,6,8,10,11$ and 13 were reverse scored. Purpose in life scale items 2, 3, 5, 6, 7, 11 and 14 reverse scored. Self-acceptance item numbers 3, 4, 7, 9, 10, 11 and 14 were reversed scored.

\subsection{Statistical Analysis}

In this research Statistical Package for Social Sciences SPSS 22 was used to analyze data. Statistical techniques used to get results.

\subsection{Ethical Considerations}

All the ethics of psychological research was followed. Informed consent was given and participants were free to allow leaving questionnaire when they feel any hesitation. Debriefing was given to participants. One or two unfilled item containing questionnaires were also discarded from research.

\section{Results}

There were 200 overall participants of current study including 102 males and 98 females. They include 98 participants within the age of 15-20 years and 102 within 21-26 years. Total of 95 participants were from Government Sadiq College Women University, 52 from Islamia University Bahawalpur, 49 from Govt. Sadiq Egerton College, and four from Allama Iqbal College, Bahawalpur (Table 1). 
Table 1 Demographics of Study Participants

\begin{tabular}{|c|l|l|l|}
\hline \multirow{3}{*}{ Gender } & \multicolumn{1}{|c|}{ Variables } & \multicolumn{1}{|c|}{$\boldsymbol{f}$} & \multicolumn{1}{c|}{$\%$} \\
\cline { 2 - 5 } & Male & 102 & 51 \\
\cline { 2 - 5 } & Female & 98 & 49 \\
\hline \multirow{4}{*}{ Inge } & $15-20$ & 98 & 49 \\
\cline { 2 - 5 } & $21-26$ & 102 & 51 \\
\hline \multirow{5}{*}{} & Government Sadiq College Women University & 95 & 47.5 \\
\cline { 2 - 5 } & Islamia University Bahawalpur & 52 & 26 \\
\cline { 2 - 5 } & Allama Iqbal College & 4 & 2 \\
\cline { 2 - 5 } & Govt. Sadiq Egerton College & 49 & 24.5 \\
\hline
\end{tabular}

\subsection{Correlation Outcomes}

Life satisfaction was positively correlated but not significant with environmental mastery, psychological wellbeing, positive relations, self-acceptance, and purpose in life. Psychological wellbeing is significantly $(p<0.01)$ positively correlated with environmental mastery, positive relations, purpose in life and self-acceptance. Environmental mastery was significantly $(\mathrm{p}<0.01)$ positively correlated with positive relations, purpose in life and self-acceptance. Positive relations were significantly $(\mathrm{p}<0.01)$ positively correlated with purpose in life and self-acceptance. Purpose in life was significantly $(\mathrm{p}<0.01)$ and positively correlated with self-acceptance (Table 2). The results revealed that there were significant gender differences were found in psychological wellbeing $(\mathrm{M}=223.1, \mathrm{SD}=24.8)$ and life satisfaction $(\mathrm{M}=$ $25.6, \mathrm{SD}=5.35$ ). Psychological wellbeing and life satisfaction were more in females than men (Table 3).

Table 2 Correlations of Life Satisfaction, Psychological Wellbeing, Environmental Mastery, Positive Relations, Purpose in Life and Self-acceptance

\begin{tabular}{|l|c|c|c|c|c|}
\hline \multicolumn{1}{|c|}{ Variables } & $\mathbf{1}$ & $\mathbf{2}$ & $\mathbf{3}$ & $\mathbf{4}$ & $\mathbf{5}$ \\
\hline Life Satisfaction & & & & & \\
\hline Psychological wellbeing & 0.84 & & & & \\
\hline Environmental Mastery & 0.65 & $0.663^{* *}$ & & & \\
\hline Positive Relations & 0.12 & $0.801^{* *}$ & $0.357^{* *}$ & & \\
\hline Purpose in Life & 0.102 & $0.803^{* *}$ & $0.388^{* *}$ & $0.516^{* *}$ & \\
\hline Self-acceptance & 0.110 & $0.830^{* *}$ & $0.386^{* *}$ & $0.567^{* *}$ & $0.585^{* *}$ \\
\hline
\end{tabular}

Table 3 Independent Sample T-Test of Gender differences for Life Satisfaction and Psychological Wellbeing

\begin{tabular}{|c|c|c|c|c|c|c|c|}
\hline Variables & $\begin{array}{c}\begin{array}{c}\text { Male } \\
(N=102)\end{array} \\
M(S D)\end{array}$ & $\begin{array}{c}\text { Female } \\
\frac{(N=98)}{M(S D)}\end{array}$ & $\begin{array}{c}\text { Mean } \\
\text { Difference }\end{array}$ & $t(198)$ & $p$ & $\frac{95 \%}{L L}$ & $\frac{C I}{U L}$ \\
\hline Life Satisfaction & $22.1(6.11)$ & $25.6(5.35)$ & -1.44 & -1.77 & 0.07 & -3.04 & 0.16 \\
\hline Psychological Wellbeing & $215.6(29.4)$ & $223.1(24.8)$ & -7.52 & $-1.95^{*}$ & 0.05 & -15.2 & 0.07 \\
\hline
\end{tabular}




\subsection{Regression Outcomes}

The three predictor model was able to account for $0.41 \%$ variance in purpose in life, $F(2,198)=45.646, p<.001, \mathrm{R}^{2}=$ $0.411,95 \% \mathrm{Cl}$. Among three predictor variable, positive relations and self-acceptance has a significant $(p<0.001)$ correlation with purpose in life. But self-acceptance is greater predictor of purpose in life.

Table 4 Summary of Multiple Regression Analysis with Purpose in Life as Dependent Variable

\begin{tabular}{|l|c|c|c|c|c|c|}
\hline Predictor Variables & B & $\boldsymbol{B}$ & $\boldsymbol{t}$ & $\boldsymbol{R}^{\mathbf{2}}$ & $\boldsymbol{F}$ & $\boldsymbol{P}$ \\
\hline Constant & 12.0 & & 3.11 & 0.411 & 45.65 & 0.002 \\
\hline Environmental Mastery & 0.167 & 0.152 & 2.51 & & & 0.013 \\
\hline Positive Relations & 0.221 & 0.240 & 3.55 & & & 0.000 \\
\hline Self-acceptance & 0.361 & 0.390 & 5.69 & & & 0.000 \\
\hline
\end{tabular}

\section{Discussion}

The current research investigates how life satisfaction is associated with psychological wellbeing. This study also explains the gender differences between these variables. This study aimed to find out the relationship between life satisfaction and psychological wellbeing of young adults. The results indicated that life satisfaction is positively linked to environmental mastery, purpose in life, positive relations with others and self-acceptance in general psychological wellbeing. The results were positively correlated but not significant. Young adults face many changes in their life. Their social circle increased, childhood role changed with maturity, independence and increase responsibilities are major issue of this developmental stage [14].

Life satisfaction is not just a single concept. It is multidimensional entity. Many researchers discuss satisfaction with job, marital satisfaction, satisfaction with school life and satisfaction with family under this term. A significant ( $p<0.01)$ positive correlation was found between environmental mastery, positive relations with others, purpose in life and selfacceptance that is similar in other researches. The results of the present study revealed that there are significant gender differences on levels of life satisfaction and psychological wellbeing of young adults which is agreement with some previous research. Some other researches revealed that female are generally less satisfied than men [15,16]. According to this study self-acceptance and positive relations is major predictor of purpose in life of young adults.

Adulthood period of life is very important phrase of life due to changes in cognitive, psychological and physical aspects of life. Because young adults are productive part of society and if they are satisfied in early life it will be beneficial for them and for society too. Females have to face more problems like to give time to home, to society and increased social circle. People who are psychologically healthy can deal better with life difficulties and have satisfied life. Kim et al., (2017) claimed that less physical complaint, more positive relationships and positive psychological health is predictor of life satisfaction and depression, stress and anxiety are very weak predictor of life satisfaction [17]. Psychologically healthy people have the ability to maintain healthy relationships, self-acceptance, and purpose in life. Socio- economic status also has great impact on life satisfaction. There is a positive relationship between life satisfaction and socioeconomic status. Life satisfaction is same at different countries. Different researcher found no difference across different cultures [18].

Psychological wellbeing across life remains same. Different researches concluded that psychological wellbeing scores for different age group are not significant. Findings from the existing studies found that aging does not increase or decrease positive functioning in life. Education also had impact on wellbeing of adults [19]. Educated female has more perception of wellbeing than women with lower education. That is in agreement with present study that educated females have higher scores on psychological wellbeing. Flowers (2002) concluded that there is a difference of psychological wellbeing of freshman and seniors. Seniors have more wellbeing. And have more mastery to deal effectively with difficult life situations [20].

Present study revealed that positive relations and purpose in life is positively related with life satisfaction. This is also concluded by others. Life satisfaction may be increased by peer acceptance, family environment and positive relationships. When one accepts himself his self-esteem become high. Previous researches suggest that self-esteem is better predictor of subjective wellbeing and life satisfaction of adults. They also found opposite results as low selfesteem is linked to higher satisfaction and wellbeing [21]. Current study finds out that the more people have mastery of 
environment, acceptance of him or herself, have purpose in life and having positive relations with other people are more satisfied with their life.

\section{Conclusion}

People who are psychologically healthy have great sense of control on their environment and accept their self. Who have purpose in life and positive relations with others are healthy personalities. Psychologically healthy people are more satisfied with their life. This research finds out that life satisfaction is positively linked to environmental mastery, purpose in life, positive relations with others and self-acceptance. overall females are more psychologically healthy and satisfied with life.

\section{Limitations and suggestions}

There was purposive sampling technique used for this study and only educated people participated while uneducated were ignored. Sample size was small and study conducted only in Bahawalpur City so that's why we cannot generalize the results to all population. Marital status and income effect on variable should be checked. Random sampling with maximum sample size should be maximize. Educated and uneducated both people should include in study and checked out difference of their wellbeing and life satisfaction.

\section{Compliance with ethical standards}

\section{Acknowledgments}

Many gratitude acknowledged to management of Women University Bahawalpur for support in this research.

\section{Disclosure of conflict of interest}

There is no conflict of interests to declare from anyone of authors.

\section{Statement of informed consent}

It is notified that informed consent was obtained from all individual participants included in the study.

\section{References}

[1] Adams M. The Relationship Between God Representations and Psychological Well-Being. 2019.

[2] Hui NNA. Talent Development in Children and Adolescents: Roles of Gifted Characteristics, Self-efficacy, and Life Satisfaction. In: Annual Hotung Lecture (AHL) cum Biennial Parent Conference. 2020.

[3] Gómez-López M, Viejo C, Ortega-Ruiz R. Psychological well-being during adolescence: Stability and association with romantic relationships. Front Psychol. 2019; 10: 1772.

[4] Sugiura Y, Sugiura T. Mindfulness as a moderator in the relation between income and psychological well-being. Front Psychol. 2018; 9: 1477.

[5] Bingöl TY, Batik MV. Unconditional Self-Acceptance and Perfectionistic Cognitions as Predictors of Psychological Well-Being. J Educ Train Stud. 2019; 7(1): 67-75.

[6] Twenge JM. More time on technology, less happiness? Associations between digital-media use and psychological well-being. Curr Dir Psychol Sci. 2019; 28(4): 372-9.

[7] Fernández-Portero C, Alarcón D, Padura ÁB. Dwelling conditions and life satisfaction of older people through residential satisfaction. J Environ Psychol. 2017; 49: 1-7.

[8] Twenge JM, Martin GN, Campbell WK. Decreases in psychological well-being among American adolescents after 2012 and links to screen time during the rise of smartphone technology. Emotion. 2018; 18(6): 765.

[9] Chitra T, Karunanidhi S. The impact of resilience training on occupational stress, resilience, job satisfaction, and psychological well-being of female police officers. J Police Crim Psychol. 2021; 36(1): 8-23.

[10] Hernandez R, Bassett SM, Boughton SW, Schuette SA, Shiu EW, Moskowitz JT. Psychological well-being and physical health: Associations, mechanisms, and future directions. Emot Rev. 2018; 10(1): 18-29. 
[11] Verner-Filion J, Vallerand RJ, Amiot CE, Mocanu I. The two roads from passion to sport performance and psychological well-being: The mediating role of need satisfaction, deliberate practice, and achievement goals. Psychol Sport Exerc. 2017; 30: 19-29.

[12] Liu D, Baumeister RF, Yang C, Hu B. Digital communication media use and psychological well-being: A metaanalysis. J Comput Commun. 2019; 24(5): 259-73.

[13] Maddux JE. Subjective well-being and life satisfaction: An introduction to conceptions, theories, and measures. Routledge/Taylor \& Francis Group. 2018.

[14] Bernstein BO, Lubinski D, Benbow CP. Academic acceleration in gifted youth and fruitless concerns regarding psychological well-being: A 35-year longitudinal study. J Educ Psychol. 2021; 113(4): 830.

[15] Hausler M, Strecker C, Huber A, Brenner M, Höge T, Höfer S. Distinguishing relational aspects of character strengths with subjective and psychological well-being. Front Psychol. 2017; 8: 1159.

[16] Lindqvist E, Östling R, Cesarini D. Long-run effects of lottery wealth on psychological well-being. Rev Econ Stud. 2020; 87(6): 2703-26.

[17] Kim J, Lee S, Chun S, Han A, Heo J. The effects of leisure-time physical activity for optimism, life satisfaction, psychological well-being, and positive affect among older adults with loneliness. Ann Leis Res. 2017; 20(4): 40615.

[18] Horwood S, Anglim J. Problematic smartphone usage and subjective and psychological well-being. Comput Human Behav. 2019; 97: 44-50.

[19] Erfani SS, Abedin B. Impacts of the use of social network sites on users' psychological well-being: A systematic review. J Assoc Inf Sci Technol. 2018; 69(7): 900-12.

[20] Dejonckheere E, Mestdagh M, Houben M, Rutten I, Sels L, Kuppens P, et al. Complex affect dynamics add limited information to the prediction of psychological well-being. Nat Hum Behav. 2019; 3(5): 478-91.

[21] Huang C. Time spent on social network sites and psychological well-being: A meta-analysis. Cyberpsychology, Behav Soc Netw. 2017; 20(6): 346-54. 